\title{
Whole Blood or Product Preparation
}

National Cancer Institute

\section{Source}

National Cancer Institute. Whole Blood or Product Preparation. NCI Thesaurus. Code C133293.

The preparation of whole blood or any of its components. 